UDC 364.4

LBC 60.561 .7

\title{
MODERN MARKET OF SOCIAL SERVICES: THE EXPERIENCE OF AREA STUDIES ${ }^{1}$
}

\author{
Nataliya A. Nikolenko \\ Volgograd State University, Volgograd, Russian Federation \\ Yana I. Serova \\ Volgograd State University, Volgograd, Russian Federation
}

\begin{abstract}
The study investigates the changes taking place in the domestic market of social services expressed in the appearance of "new players" in the form of socially oriented non-profit organizations (SO NPO) within its field in addition to public institutions for social protection and social services of the population. The authors identify the advantages and disadvantages of SO NGO compared to government organizations and social services, describe the processes of shadow economy expansion to the social services market and formation of regional "quasi-markets". The empirical part of the article is based on the data of two studies conducted in the form of indepth interviews. First, with experts on "Practices of interaction and prospects of cooperation between NPO and government organizations of social services in the Volgograd region", $N=52$ (27 representatives of the public sector, 25 representatives of NPO, January-March 2018). Then with recipients of social services from government organizations and clients of SO NPO on the theme "Availability and quality of paid and free social services provided in the Volgograd region for retiring aged women" $N=46,60$ years and older (21 people-clients of SO NPO, 25 people-recipients of social services. services, October 2017 - January 2018). The analysis of these in-depth interviews with experts allowed to draw the following conclusions. There is a duplication of functions of the organizations of public and non-public sectors providing social services to the population. The activities of modern SO NPO operating in the social services market contain innovative and commercial components. The expansion of the "platform" of the social services market does not yet lead to full competition between organizations, encouraging them to constantly improve the quality of services. The analysis of in-depth interviews with recipients of social services from government organizations and customers of SO NPO showed that the commercialization of activities of SO NPO does not make social services more accessible to those who are in need of them. There is the necessity of changes in the way social services are being provided in the Volgograd region as they do not meet the needs of women of retirement age, do not take into account their level of income and material well-being.

Key words: social services, social services market, third age, retirement age, "third age" women, commercialization of social services, socially oriented non-profit organizations, government organizations of social services.
\end{abstract}

УДК 364.4

\section{СОВРЕМЕННЫЙ РЫНОК СОЦИАЛЬНОГО ОБСЛУЖИВАНИЯ НАСЕЛЕНИЯ: ОПЫТ РЕГИОНАЛЬНОГО ИССЛЕДОВАНИЯ ${ }^{1}$}

\author{
Наталия Александровна Николенко \\ Волгоградский государственный университет, г. Волгоград, Российская Федерация \\ Яна Игоревна Серова \\ Волгоградский государственный университет, г. Волгоград, Российская Федерация
}


Аннотация. В статье исследуются изменения, происходящие на отечественном рынке социальных услуг, выразившиеся в появлении на его поле помимо государственных учреждений по социальной защите и социальному обслуживанию населения «новых игроков» в виде социально ориентированных некоммерческих организаций (СО НКО). Выявляются преимущества и недостатки СО НКО по сравнению с государственными организациями социального обслуживания населения, описываются процессы «теневизации» рынка социальных услуг и формирования региональных «квазирынков». Эмпирическая часть статьи базируется на данных двух исследований, проведенных в форме глубинных интервью: с экспертами на тему «Практики взаимодействия и перспективы развития сотрудничества СО НКО с государственными организациями социального обслуживания в Волгоградской области», $N=52$ (27 представителей государственного сектора, 25 представителей СО НКО, январь - март 2018 г.); с получателями социальных услуг от государственных учреждений и клиентами СО НКО на тему «Доступность и качество предоставляемых женщинам пенсионного возраста платных и бесплатных социальных услуг, оказываемых в Волгоградском регионе», $N=46$, от 60 лет и старше (21 чел. - клиенты СО НКО, 25 чел. - получатели соцуслуг, октябрь 2017 г. - январь 2018 г.). Анализ данных глубинных интервью с экспертами позволил сделать следующие выводы: происходит дублирование функций организаций государственного и негосударственного секторов, оказывающих социальные услуги населению; деятельность современных СО НКО, работающих на рынке социальных услуг, содержит инновационную и коммерческую составляющие; расширение рынка социальных услуг пока не приводит к полноценной конкуренции между организациями, побуждающей их к постоянному повышению качества услуг. Анализ данных глубинных интервью с получателями социальных услуг от государственных учреждений и клиентами СО НКО показал, что коммерциализация деятельности СО НКО не делает социальные услуги более доступными для тех, кто в них нуждается; необходимы изменения способов предоставления социальных услуг в Волгоградской области, поскольку они не удовлетворяют потребности женщин пенсионного возраста, не учитывают их уровень дохода и материального благополучия.

Ключевые слова: социальные услуги, рынок социальных услуг, третий возраст, пенсионный возраст, женщины «третьего возраста», коммерциализация социальных услуг, социально ориентированные некоммерческие организации, государственные организации социального обслуживания населения.

Введение. В 90-е гг. XX в. П. Ласлетт предложил классификацию периодов жизненного цикла человека, выделив «третий возраст» (от 55-60 лет до 70-75 лет) и «четвертый возраст» (старше 75 лет). Особенность представителей «третьего возраста», по мнению ученого, сохранение функциональной независимости, в то время как представители «четвертого возраста» являются уже людьми реально пожилыми и социальной активностью, как правило, не отличаются [21]. Этой позиции стали придерживаться многие исследователи, в том числе и отечественные ученые $[2 ; 14 ; 18]$. Разделяя указанную точку зрения, авторы статьи соглашаются, что «россияне вступают в старость, не защищенные “подушкой материальной безопасности”, - у большинства нет возможности сделать накопления, которые помогли бы обеспечить старость. Когда наступает третий возраст, они оказываются полностью зависимыми от поддержки государства и/или родственников. Отсюда чувство беспомощности и заниженные оценки статуса» $[10]$.

Следует подчеркнуть, что смена статусных позиций человека на протяжении жизни - процесс неизбежный. Очевидным является факт, что переход индивида от одних к другим социальным ролям должен быть постепенным по мере приобретения жизненного опыта. Нельзя не принимать в расчет и того, что все факты предшествующей жизни человека (выбранные стратегии поведения, цели, реакции на вызовы внешней среды и др.) не могли не отразиться на характеристиках положения, в котором человек оказался, «переступив» черту пенсионного возраста. Так, стремление женщин в молодые и средние годы жизни сочетать семейную и профессиональную занятость приводит к избранию большинством из них стратегии «удобной работы» (близости к дому, скользящему графику, неполному рабочему дню) и, как правило, мало оплачиваемой [2]. Подобная стратегия в совокупности с рождением детей и использованием отпусков по уходу за ними в течение трех лет снизили пенсионные накопления нынешних пенсионерок по сравнению с женщинами, не имеющими детей или не использовавшими этот отпуск, на 7-11, 14-21, 21-30 \% соответственно в случае рождения одного, двоих, троих детей [3]. 
Ситуация осложняется в случае отсутствия у женщины супруга, друзей, любимого дела (хобби) и появившейся потребностью в силу возраста (а иногда здоровья) в заботе, помощи. Беспокоит изменение привычного образа жизни, ощущение «социальной изоляции», снижение способности к социальной адаптации [9]. Справиться с психологическим дискомфортом становится самостоятельно достаточно трудно. На помощь могут прийти родственники, друзья или представители организаций, предоставляющие социальные услуги.

Современный рынок социальных услуг: что изменилось с приходом СО НКО? Российский рынок социальных услуг представляет собой динамично изменяющуюся структуру, которая, отвечая на вызовы современного общества, пытается адекватно удовлетворять возрастающие потребности социума. На рынке появляются «новые игроки» в лице СО НКО в связи с ростом потребительского спроса на социальные услуги (в том числе и из-за увеличения количества пожилых людей), с которым государственным организациям, ограниченным стандартами, определяющими перечень набора услуг, форм и объема их предоставления, справляться становится сложнее. Ориентация на определенную категорию граждан и адресный подход при выборе клиента, выделенные зарубежными учеными [20] как специфические черты СО НКО, на наш взгляд, таковыми не являются, так как государственные организации имеют те же характеристики. Однако СО НКО по сравнению с государственными организациями социального обслуживания населения все же имеют определенные преимущества: более широкие возможности для комплексного удовлетворения потребностей получателя социальных услуг, поскольку не стеснены количественными показателями плана государственного задания. СО НКО может «выстраивать» график посещений клиента в зависимости от его потребностей, в то время как у социального работника из госучреждения число посещений строго регламентировано. Кроме того, СО НКО имеет право на использование в качестве источников финансирования различных ресурсов: фондов, частных компаний, добровольческих пожертвований, государственных грантов и др.
Ряд ученых видит в появлении СО НКО «запуск» инновационного механизма по разгосударствлению рынка социальных услуг, который должен способствовать повышению конкурентоспособности организаций, поиску новых форм работы и расширению спектра предоставляемых социальных услуг и их доступности $[1 ; 4 ; 5 ; 8]$. Другие исследователи ситуацию оценивают более сдержанно, подчеркивая влияние фактора «непрямого государственного управления» СО НКО, механизм которого четко проявляется [11]. СО НКО стоят перед выбором источников финансирования, и, если не находят иных, обращаются за помощью к государству, которое в этом случае сохраняет прерогативы не только в регулировании финансового обеспечения некоммерческих организаций, но и в формировании системы их социального обслуживания, индивидуальных программ получателя социальных услуг, а также в определении перечня услуг, их качества и объема [7].

Подобная зависимость способствует формированию региональных «квазирынков» социальных услуг самими же некоммерческими организациями [19]. «Квазирынки» являются своего рода «институциональными структурами государственного сектора экономики, созданными для достижения эффективности» [16]. Однако увеличение состава участников рынка социальных услуг за счет допуска некоммерческих организаций не гарантирует создания условий свободной конкуренции и отбора тех организаций, которые будут удовлетворять потребности клиентов в большей степени. Объясняется это проявлением «теневизации» рынка социальных услуг, наличием теневого поведения, проявляющегося в выстраивании разнообразными социальными игроками «неформальных отношений», и модификацией всего механизма функционирования рынка социальных услуг. В результате нерыночный товар (услуга, социальные блага) на теневом рынке превращается в объект рыночных операций, перестает быть доступным для всех, становится предметом «купли-продажи» [17].

«Продажа» социальных услуг и возможности их приобретения женщинами «третьего возраста» и старше. Женщины в сравнении с мужчинами раньше на 5 лет (с 
выходом на пенсию по возрасту) сталкиваются с проблемами, связанными с изменением их социальных статусов, с вынужденным снижением социальных амбиций, субъективным осознанием «психологического бессилия в осуществлении желаний», а порой одиночества и физической беспомощности [9]. Государство по мере сил пытается помочь гражданам в преодолении проблем, осложняющих жизнь, предоставляя возможность получения социальных льгот, услуг, материальных выплат. Напомним, что средний размер пенсий в РФ в 2017 г. составил 12080 руб. 90 коп.; выплаты по старости - 12830 руб., а по инвалидности -8040 рублей [13]. Исходя из среднестатистических представлений о материальном уровне женщин «третьего возраста» и старше, попытаемся проследить их возможности в решении насущных проблем посредством получения социальных услуг, которые могут предоставляться пенсионерам платно и бесплатно государственными и негосударственными организациями. Право на получение бесплатных услуг и их объем определяется нормативными документами с учетом индивидуальных особенностей клиента. Данное правило действует на территории всех субъектов РФ, в том числе и в Волгоградской области, в которой проживают почти 780 тысяч пенсионеров (31\% от общей численности населения). При этом в общей численности пенсионеров удельный вес мужчин и женщин соответственно составляет 31 и $69 \%$, а лиц в возрасте от 80 лет и старше $11,1 \%$ (85 тысяч человек). Из них $77 \%$ женщины [13].

Безусловно, не все люди, достигшие пенсионного возраста, прекращают свою трудовую деятельность. Часть пенсионеров (в том числе и женщин) по разным причинам продолжают работать (по материальным соображениям, желая оставаться включенными в систему общественных коммуникаций, опасаясь оказаться в условиях полной или частичной «социальной изоляции» и др.) [18].

Мы же остановимся на изучении той части женщин «третьего возраста», которые не работают и нуждаются в оказании социальных услуг или пользуются ими. Идея вовлечения некоммерческих организаций в пространство рынка социальных услуг сомнений не вызывает, достаточно провести параллель с период НЭПа и оценить полученный экономический эффект [6]. Предполагалось также, что государственные и некоммерческие организации займут свои ниши на рынке социальных услуг и будут выступать в качестве взаимодополняющих структур. Однако, судя по стратегиям, выбранным некоторыми СО НКО, синхронизации действий пока на практике не наблюдается [12]. К примеру, в результате слабой информированности о возможностях СО НКО предоставлять бесплатные услуги и/или их полном перечне, клиенты вынуждены оплачивать социальные услуги, а порой отказываться от них по финансовым соображениям ввиду ограниченности или отсутствия средств, накапливая перечень неудовлетворенных потребностей. Хотя предполагалось, что от увеличения поставщиков социальных услуг их получатели, и прежде всего женщины, которые по сравнению с мужчинами обращаются за помощью чаще [2], должны выиграть. Что же происходит на самом деле?

Постановка задач и методы исследования. В целях изучения практик поведения государственных и некоммерческих организаций на рынке социальных услуг, степени удовлетворенности клиентов качеством предоставляемых услуг и их доступностью, авторами данной статьи были проведены два социологических исследования методом глубинного интервью: 1) глубинные интервью с экспертами на тему «Практики взаимодействия и перспективы развития сотрудничества $\mathrm{CO}$ НКО с государственными организациями социального обслуживания в Волгоградской области»; критерии выборки: статус работника в системе социальной защиты и социального обслуживания населения (руководитель организации, специалист по взаимодействию государственного и негосударственного секторов, специалисты по оказанию социальных услуг) и опыт работы по предоставлению социальных услуг; $N=52$ (27 представителей государственного сектора, 25 представителей СО НКО, январь - март 2018 г.); 2) глубинные интервью с получателями социальных услуг и клиентами СО НКО на тему «Доступность и качество предоставляемых женщинам пенсионного возраста платных и бес- 
платных социальных услуг, оказываемых в Волгоградском регионе», $N=46$, от 60 лет и старше (21 чел. - клиенты СО НКО, 25 чел. получатели соцуслуг, к которым применялись формы обслуживания «надомная» и «полустационарная», октябрь 2017 г. - январь 2018 г.).

Результаты исследования. Анализ полученных данных позволил выявить устойчивое мнение представителей государственного сектора о том, что СО НКО имеют ресурсные возможности для оказания социальных услуг и предложения «инновационных» форм работы с населением. По мнению сотрудников государственных организаций, «социиально ориентированные некоммерческие организачии должны рассматриваться как равноправные поставщиики социальных услуг. Занять собственное место в социальной сфере - своеобразного "буфера" между государством и населением» (руководитель государственной организации социального обслуживания населения, ж., 50 лет). И фактом своего существования, и деятельностью СО НКО должны стимулировать всех поставщиков социальных услуг к улучшению качества своей работы. Однако пока «здоровой конкуренции не получается, идет проиесс перераспределения функиий, а иногда просто их копирование» (специалист по работе с негосударственными организациями социального обслуживания, ж., 34 года).

Многие СО НКО не утруждают себя поиском и привлечением новых клиентов, используют стратегии «выжидания», «переманивания», забывая об иной миссии своего выхода на рынок социальных услуг. Более того, «СО НКО часто используют клиентскую базу государственных учреждений. И путем распространения информации о себе при помощи рекламы, буклетов и визиток “уводят” потребителей сочиальных услуг из государственного в негосударственный сектор сочиального обслуживания) (руководитель государственной организации социального обслуживания, ж., 45 лет). При этом некоторые СО НКО, не найдя собственной ниши на рынке социальных услуг, дублируя функции государственных учреждений, просят оказать поддержку в их деятельности. При этом чаще «сотрудники СО НКО обращаются не за методической помощьью, кото- рая могла бы помочь в практической работе с населением, а по вопросам оформления документов» (специалист по взаимодействию с некоммерческим сектором, ж., 49 лет).

Оправдывая применяемые стратегии, руководители $\mathrm{CO} \mathrm{HКО,} \mathrm{в} \mathrm{свою} \mathrm{очередь,} \mathrm{жа-}$ луются на то, что «вступить в реестр региональных поставщиков соииальных услуг не просто. К некоммерческим организациям предъявляются очень жесткие требования по кадровому составу, имущественным показателям, объему сочиальных услуг и прочее» (руководитель СО НКО, м., 47 лет). Но, даже вступив в этот реестр, информация о СО НКО государственными организациями распространяется неэффективно используются каналы Интернет, которые трудно доступны для пожилых граждан, как правило, не достаточно хорошо владеющих навыками работы с компьютером. В результате женщины «третьего возраста» и старше, являясь потенциальными или реальными потребителями социальных услуг, не получают информацию для составления полной картины о разнообразии социальных услуг на региональном рынке, условиях их получения, тарифах и организациях их предоставляющих. Поэтому, как правило, предпочтения клиенты традиционно отдают государственным организациям социального обслуживания населения. «Люди по-старинке больше доверяют государственным организациям. Хотя у нас и иены на некоторые услуги такие же, как и в государственных организациях, услуги разнообразней и качество хорошее. Относятся с недоверием, пока не убедятся, что им желают только добра» (руководитель СО НКО, ж., 51 год).

Напомним, что СО НКО и государственные организации могут оказывать платные и бесплатные услуги. Виды и цены платных услуг в государственных учреждениях строго определены, в СО НКО они могут устанавливаться на основе локальных внутренних приказов. Бесплатные услуги предоставляются на основе заключений работников центров социальной защиты населения, определяющих необходимость их предоставления, направленность и объем. Составляется индивидуальная программа получателя социальных услуг. 
Поэтому клиентам СО НКО и получателям государственных услуг приходится доплачивать за те услуги, которые не вошли в программу, но, по мнению пенсионеров, им необходимы.

Анализ содержания тарифных расценок на социальные услуги, размещенных на сайтах СО НКО, действующих на территории Волгоградской области, позволил заключить, что цены на них, кажущиеся на первый взгляд вполне приемлемыми, на самом деле доступными оказываются не для всех клиентов.

В то же время надо признать, что предлагаемый негосударственными организациями набор платных услуг весьма разнообразен. Например, СО НКО оказывают социально-педагогические услуги по обучению флористике, фотографированию. Вместе с тем были обнаружены услуги, предоставляемые государственными и негосударственными организациями, одного ценового ряда и направленности стоимостью от шестидесяти до трехсот рублей: «содействие в прохождении медицинской комиссии», «одевание/раздевание», «оказание помощи в получении юридических услуг» (услуга оказывается АНО $\mathrm{COH}$ «Территория добра» и госорганизациями) [15]. Достаточно дорогими услугами для пенсионеров оказались «помощь в измерении сахара крови глюкометром», «помощь в закапывании капель в глаза, нос, уши» [15]. Несмотря на то что каждая услуга стоит от девяти до тринадцати рублей, она востребована несколько раз в день на протяжении длительного времени, в итоге услуга оценивается с точки зрения пенсионеров как дорогая: «За месяи я заплатила около тысячи рублей. Это очень дорого» (клиент СО НКО, ж., 78 лет).

Что касается социально-бытовых услуг, то их спектр тоже достаточно широк, но ценовой ряд доступен только определенной категории граждан с достатком выше среднего. Приведем пример перечня социально-бытовых услуг СО НКО с указанием их цен для общей характеристики изучаемой ситуации. Услуги предоставляются АНО СОН «Опора», АНО «ЦПН “Солнечный Дом”», АНО СОН «Территория добра»: услуга «машинная стирка белья (стирка, полоскание, вывешивание)» - 1 загрузка от 32 до 35 руб.; «стирка ручная с полосканием и вывешиванием белья (до 20 мин)»- 64 руб.; «вызов мастера по ремонту и обслуживанию бытовой техники, газового оборудования и сантехники с посещением организации (1 услуга - 1 час): в пределах района проживания клиента» - 50 руб.; «за пределами района проживания» - 120 руб., «помощь в уходе за могилами», «уборка приусадебных участков» - 1 час $-235,40$ рублей [15].

Если учесть, что в 2018 г. средний размер пенсии в Волгоградской области равен 12,925 руб., прожиточный минимум по региону за 2017 г. был самый высокий только во втором квартале - 7 760,0 руб., а к концу года снизился до 7100 руб. [13], в размер потребительской корзины пенсионера не вмещаются все расходы на питание, лекарства, ЖКХ, транспорт, одежду, обувь и хозяйственно-бытовые принадлежности, то становится очевидным, что обращаться за предоставлением платных услуг пенсионеры будут в случае крайней необходимости.

Как показал анализ данных глубинных интервью, качеством оказываемых услуг (платных и бесплатных) получатели государственных услуг и клиенты СО НКО в целом довольны. При этом диапазон получаемых услуг женщинами оказался весьма широк: это и социально-бытовые услуги (покупка и доставка промышленных товаров, уборка квартиры, приготовление пищи и др.), и социально-медицинские (вызов медицинских работников на дом, сопровождение в медицинские организации и др.), и социально-правовые (содействие в оформлении документов, льготных пособий), и социально-психологические (коммуникативное общение, психологическая поддержка и пр.). Причем большинство информантов отметили, что очень нуждаются именно в социально-психологических услугах, так как многие проживают одни: «Социальный работник у меня бесценный, чувствую себя хоть кому-то нужной» (клиент госучреждений, ж., 80 лет). «Помогающая мне женщина вежливая и очень хорошо знает свое дело» (клиент СО НКО, ж., 75 лет).

В целом позитивная тональность о качестве услуг присутствовала у всех информантов - женщин «третьего возраста» и старше. Но и в отношении расценок на социальные услуги они тоже были солидарны: «Качество 
услуг хорошее. Жаловаться на это не могу. Не устраивают только высокие тарифы на обслуживание. Очень дорого» (клиент СО НКО, ж., 83 года).

«Благодарю за оказание мне поддержки, внимания. Знаю, что хоть государство меня не бросит. Но хотелось бы снижения тарифов. Получаемой пенсии не на все хваmaem» (клиент госучреждений, ж., 71 год).

«Спасибо, что помогли в оформлении и восстановлении документов. Сама бы я не смогла это сделать. Пришлось, конечно, потратиться. Хотелось бы, чтобы цены на услуги были более демевые» (клиент СО НКО, ж., 62 года).

В то же время следует подчеркнуть, что информанты проявляют больше доверия к государственным организациям и свои социальные ожидания связывают с государством.

Заключение. Общемировая тенденция увеличения численности пожилых людей характерна как для России в целом, так и для Волгоградской области, в которой проживают почти 780 тысяч пенсионеров, что составляет $31 \%$ от общей численности населения. Количественный рост пожилых людей влечет за собой целый ряд задач, решать которые на уровне региона необходимо быстро и качественно. Одним из возможных путей государственные органы власти видят в структурно-функциональном изменении рынка социальных услуг, именно по этой причине в сферу социального обслуживания стали привлекаться СО НКО. Однако освоение ими новой сферы деятельности привело не только к предоставлению более разнообразных услуг в сравнении с государственными учреждениями, но и к коммерциализации деятельности СО НКО.

В результате «выигрыш» получателей социальных услуг (в нашем случае женщин «третьего возраста» и старше) может быть интерпретирован двояко. С одной стороны, предоставляется широкий спектр в целом качественных услуг, а с другой - материальные возможности клиентов ограничены и не учтены поставщиками социальных услуг. Однако в силу жизненной необходимости, несмотря на ограниченность материальных средств, пожилые люди вынуждены «включиться» в рыночные отношения. Необходимость в пересмот- ре ценовой политики оказания социальных услуг подтверждается высказыванием «Разве это помощь, если за всякую мелочь нам, пенсионерам, приходится платить?» (клиент госучреждений, ж., 84 года).

Проведенные глубинные интервью с экспертами позволили сделать ряд выводов: во-первых, происходит дублирование функций организаций государственного и негосударственного секторов, оказывающих социальные услуги населению; во-вторых, расширение рынка социальных услуг и выход на него СО НКО пока не приводит к полноценной конкуренции между организациями. Анализ данных глубинных интервью с получателями социальных услуг госучреждений и клиентами СО НКО показал, что коммерциализация деятельности СО НКО не приводит к большей доступности социальных услуг для нуждающихся граждан; необходимы изменения способов предоставления социальных услуг в Волгоградской области, а также пересмотр тарифов на услуги, поскольку они не удовлетворяют потребности женщин пенсионного возраста, не учитывают их уровень дохода и материального благополучия.

\section{ПРИМЕЧАНИЕ}

${ }^{1}$ Статья выполнена в рамках научного проекта № 17-13-34010 «Ресурсный потенциал некоммерческих организаций в сфере социального предпринимательства» при финансовой поддержке РФФИ и Администрации Волгоградской области.

\section{СПИСОК ЛИТЕРАТУРЫ}

1. Антропова, Ю. Ю. Роль социально ориентированных некоммерческих организаций в развитии инноваций в социальной сфере региона / Ю. Ю. Антропова, А. П. Коробейникова // Дискуссия. - 2015. - № 11 (63). - С. 64-70.

2. Балабанова, Е. С. Гендерные различия стратегий совладания с жизненными трудностями / Е. С. Балабанова // Социологические исследования. - 2002. - № 11. - С. 26-36.

3. Баскаков, В. Н. О пенсиях для мужчин и женщин: Социальные аспекты пенсионной реформы / В. Н. Баскаков, М. Е. Баскакова. - М. : Московский философский фонд, 1998. - 200 с. 
4. Белокрылова, О. С. Обеспечение доступа субъектов рынка социальных услуг к госзаказу: проблемы и решения / О. С. Белокрылова, М. А. Вахтина // Государственное и муниципальное управление. Ученые записки. -2017. - № 1. - С. 78-84.

5. Вахтина, М. А. Возможности и ограничения привлечения некоммерческого сектора к предоставлению услуг в социальной сфере / М. А. Вахтина // Вестник Самарского государственного экономического университета. - 2017. - № 9 (155). C. $60-65$.

6. Виноградов, С. В. Частное предпринимательство в период НЭПа (на материалах Поволжья) / С. В. Виноградов, Ю. Г. Ещенко, Н. И. Кулакова // Вестник Волгоградского государственного университета. Серия 4, История. Регионоведение. Международные отношения. - 2017. T. 22, № 4. - C. 139-150.

7. Власова, А. А. Проблемы и перспективы формирования и развития региональных квазирынков социальных услуг в России / А. А. Власова, А. В. Соколов // POLITBOOK. - 2017. - № 4. -C. 33-48.

8. Гусейнов, Э. К. Некоммерческие организации в сфере услуг социальной защиты: перспективы развития и проблемы государственной поддержки / Э. К. Гусейнов // Дискуссия. - 2013. № 11 (41). - С. 51-54.

9. Григорьева, И. А. Пожилые женщины: «вниз по лестнице» возраста и гендера / И. А. Григорьева // Женщина в российском обществе. 2018. - № 1. - C. 5-18.

10. Косова, Л. Третий возраст: социальное самочувствие / Л. Косова // Демоскоп. - 2015. - № 667668. - C. 1-12.

11. Мерсиянова, И. В. Преимущества НКО как поставщиков социальных услуг: апробация в российских условиях / И. В. Мерсиянова, В. Б. Беневоленский // Вопросы государственного и муниципального управления. - 2016. - № 4. - С. 7-26.

12. Николенко, Н. А. Государственный сектор и СО НКО в сфере социальной защиты населения: партнеры или конкуренты? / Н. А. Николенко, Я. И. Серова // Вестник Удмуртского университета. Социология. Политология. Международные отношения. -2017. - Вып. 2. - С. 162-166.

13. Пенсионный фонд Российской Федерации. Волгоградское отделение : офиц. сайт. - Электрон. текстовые дан. - Режим доступа: http://www.pfrf.ru/ press_center/advert_materials/ (дата обращения: 06.05.2018). - Загл. с экрана.

14. Пикулева, О. А. Самопрезентация женщин старшего возраста: российские особенности / О. А. Пикулева // Женщина в российском обществе. - 2014. - № 1. - С. 69-77.

15. Реестр поставщиков социальных услуг Волгоградской области. - Электрон. текстовые дан. - Ре- жим доступа: http://uszn.volgograd.ru/postavshchikisotsialnykhuslug/postavshchiksotsialnykhuslug/ avtonomnaya nekommercheskaya-organizatsiyasotsialnogo-obsluzhivaniya-naseleniya-territoriyadobra/ (дата обращения: 06.05.2018). - Загл. с экрана.

16. Романов, П. В. Квазирынки социальных услуг / П. В. Романов, Е. Р. Ярская-Смирнова // Социальная работа: теории, методы, практика : материалы интернет-конференций и семинаров. - 2012. № 2. - C. 14-17.

17. Рывкина, Р. В. Теневизация российского общества: причины и последствия / Р. В. Рывкина // Социологические исследования. - 2002. - № 2. C. 3-13.

18. Сонина, Ю. Пенсионеры на российском рынке труда: тенденции экономической активности людей пенсионного возраста / Ю. Сонина, М. Колосницына // Демографическое обозрение. - 2015. Т. 2. - С. 36-53.

19. Суслова, С. В. Некоммерческие производители на региональных квазирынках социальных услуг / С. В. Суслова // Вопросы государственного и муниципального управления. - 2014. - № 3. - С. 72-89.

20. Costa, A. "Social impact bonds": Implications for government and non-profit organizations / A. Costa, P. Leoci, A. Tafuro // Review of Business and Economics Studies. - 2014. - Vol. 2, № 2. - P. 58-65.

21. Laslett, P. A Fresh Map of Life: the Emergence of the Third Age / P. Laslett. - L., 1990. - 213 p.

\section{REFERENCES}

1. Antropova Yu.Yu., Korobeynikova A.P. Rol sotsialno orientirovannykh nekommercheskikh organizatsiy $\mathrm{v}$ razvitii innovatsiy $\mathrm{v}$ sotsialnoy sfere regiona [The Role of Socially Oriented Non-Profit Organizations in the Development of Innovations in the Social Sphere of the Region]. Diskussiya, 2015, no. 11 (63), pp. 64-70.

2. Balabanova E.S. Gendernye razlichiya strategiy sovladaniya s zhiznennymi trudnostyami [Gender-Conditioned Different Choice of Strategies for Coping with Difficult Situations]. Sotsiologicheskie issledovaniya, 2002, no. 11, pp. 26-36.

3. Baskakov V.N., Baskakova M.E. O pensiyakh dlya muzhchin i zhenshchin: Sotsialnye aspekty pensionnoy reformy [On Pensions for Men and Women: Social Aspects of Pension Reform]. Moscow, Moskovskiy filosofskiy fond Publ., 1998. 200 p.

4. Belokrylova O.S., Vakhtina M.A. Obespechenie dostupa subyektov rynka sotsialnykh uslug k goszakazu: problemy i resheniya [Ensuring Access of Social Services Market Entities to the Public Procurement: Problems and Solutions]. Gosudarstvennoe i munitsipalnoe upravlenie. Uchenye zapiski, 2017, no. 1, pp. 78-84. 
5. Vakhtina M.A. Vozmozhnosti i ogranicheniya privlecheniya nekommercheskogo sektora $\mathrm{k}$ predostavleniyu uslug $\mathrm{v}$ sotsialnoy sfere [Opportunities and Limitations for Engaging the NonProfit Sector in Social Services]. Vestnik Samarskogo gosudarstvennogo ekonomicheskogo universiteta, 2017, no. 9 (155), pp. 60-65.

6. Vinogradov S.V., Eshchenko Yu.G., Kulakova N.I. Chastnoe predprinimatelstvo v period NEPa (na materialakh Povolzhya) [Private Entrepreneurship during the NEP Period (Based on Materials of the Volga Region)]. Vestnik Volgogradskogo gosudarstvennogo universiteta. Seriya 4, Istoriya. Regionovedenie. Mezhdunarodnye otnosheniya [Science Journal of Volgograd State University. History. Area Studies. International Relations], 2017, vol. 22, no. 4, pp. 139-150.

7. Vlasova A.A., Sokolov A.V. Problemy i perspektivy formirovaniya i razvitiya regionalnykh kvazirynkov sotsialnykh uslug v Rossii [Problems and Prospects of Formation and Development of Regional Quasi-Markets of Social Services in Russia]. POLITBOOK, 2017, no. 4, pp. 33-48.

8. Guseynov E.K. Nekommercheskie organizatsii v sfere uslug sotsialnoy zashchity: perspektivy razvitiya i problemy gosudarstvennoy podderzhki [Non-Profit Organizations in the Sphere of Social Protection Services: Development Prospects and Problems of State Support]. Diskussiya, 2013, no. 11 (41), pp. 51-54.

9. Grigoryeva I.A. Pozhilye zhenshchiny: «vniz po lestnitse» vozrasta i gendera [Older Women: "Down the Stairs" of Age and Gender]. Zhenshchina v rossiyskom obshchestve, 2018, no. 1, pp. 5-18.

10. Kosova L. Tretiy vozrast: sotsialnoe samochuvstvie [Third Age: Social Well-Being]. Demoskop, 2015, no. 667-668, pp. 1-12.

11. Mersiyanova I.V., Benevolenskiy V.B. Preimushchestva NKO kak postavshchikov sotsialnykh uslug: aprobatsiya $\mathrm{v}$ rossiyskikh usloviyakh [Advantages of NGOs as Social Service Providers: Testing in Russian Conditions]. Voprosy gosudarstvennogo i munitsipalnogo upravleniya, 2016, no. 4, pp. 7-26.

12. Nikolenko N.A., Serova Ya.I. Gosudarstvennyy sektor i SO NKO v sfere sotsialnoy zashchity naseleniya: partnery ili konkurenty? [Public Sector and NGOs in the Field of Social Protection: Partners or Competitors?].
Vestnik Udmurtskogo universiteta. Sotsiologiya. Politologiya. Mezhdunarodnye otnosheniya, 2017, no. 2, pp. 162-166.

13. Pensionnyy fond Rossiyskoy Federatsii. Volgogradskoe otdelenie [Pension Fund of the Russian Federation. Volgograd Branch. Official Website]. URL: http://www.pfrf.ru/press_center/ advert_materials/ (accessed 6 May 2018).

14. Pikuleva O.A. Samoprezentatsiya zhenshchin starshego vozrasta: rossiyskie osobennosti [SelfPresentation of Older Women: Russian Peculiarities]. Zhenshchina $v$ rossiyskom obshchestve, 2014, no. 1, pp. 69-77.

15. Reestr postavshchikov sotsialnykh uslug Volgogradskoy oblasti [The List of Social Service Providers in the Volgograd Region]. URL: http:// uszn.volgograd.ru/postavshchikisotsialnykhuslug/ postavshchiksotsialnykhuslug/avtonomnayane kommercheskaya-organizatsiya-sotsialnogoobsluzhivaniya-naseleniya-territoriya-dobra (accessed 6 May 2018).

16. Romanov P.V., Yarskaya-Smirnova E.R. Kvazirynki sotsialnykh uslug [Quasi-Markets of Social Services]. Sotsialnaya rabota: teorii, metody, praktika : materialy internet-konferentsiy $i$ seminarov, 2012, no. 2, pp. 14-17.

17. Ryvkina R.V. Tenevizatsiya rossiyskogo obshchestva: prichiny i posledstviya [Shadowization of Russian Society: Causes and Consequences]. Sotsiologicheskie issledovaniya, 2002, no. 2, pp. 3-13.

18. Sonina Yu., Kolosnitsyna M. Pensionery na rossiyskom rynke truda: tendentsii ekonomicheskoy aktivnosti lyudey pensionnogo vozrasta [Pensioners on the Russian Labor Market: Trends in Economic Activity of Retired People]. Demograficheskoe obozrenie, 2015, vol. 2, pp. 36-53.

19. Suslova S.V. Nekommercheskie proizvoditeli na regionalnykh kvazirynkakh sotsialnykh uslug [NonCommercial Producers on Regional Quasi-Markets of Social Services]. Voprosy gosudarstvennogo $i$ munitsipalnogo upravleniya, 2014, no. 3, pp. 72-89.

20. Costa A., Leoci P., Tafuro A. "Social impact bonds": Implications for government and non-profit organizations. Review of Business and Economics Studies, 2014, vol. 2, no. 2, pp. 58-65.

21. Laslett P. A Fresh Map of Life: the Emergence of the Third Age. London, 1990. 213 p. 


\section{Information about the Authors}

Nataliya A. Nikolenko, Candidate of Sciences (Sociology), Associate Professor of Department of Sociology, Volgograd State University, Prosp. Universitetsky, 100, 400062 Volgograd, Russian Federation, nikolenko@volsu.ru.

Yana I. Serova, Candidate for a Degree, Department of Sociology, Chief Specialist of Department for Organizational and Information-Analytical Work, Center for Development and Quality Control, Committee for Population's Social Protection in the Volgograd Region, Novorossiyskaya St., 41, 400087 Volgograd, Russian Federation, jana3194@volsu.ru.

\section{Информация об авторах}

Наталия Александровна Николенко, кандидат социологических наук, доцент кафедры социологии, Волгоградский государственный университет, просп. Университетский, 100, 400062 г. Волгоград, Российская Федерация, nikolenkosocpol@volsu.ru.

Яна Игоревна Серова, соискатель кафедры социологии, Волгоградский государственный университет; главный специалист отдела организационной и информационно-аналитической работы ГКУ «Центр развития и контроля качества» комитета социальной защиты населения Волгоградской области, ул. Новороссийская, 41, 400087 г. Волгоград, Российская Федерация, jana3194@volsu.ru. 